\title{
Pigment epithelium-derived factor inhibits advanced glycation end product-induced proliferation, VEGF and MMP-9 expression in breast cancer cells via interaction with laminin receptor
}

\author{
SHIORI TSURUHISA ${ }^{1}$, TAKANORI MATSUI ${ }^{2}$, YOSHINORI KOGA ${ }^{1}$, AMI SOTOKAWAUCHI ${ }^{2}$, \\ MINORU YAGI ${ }^{1}$ and SHO-ICHI YAMAGISHI ${ }^{3}$ \\ Departments of ${ }^{1}$ Pediatric Surgery and ${ }^{2}$ Pathophysiology and Therapeutics of \\ Diabetic Vascular Complications, Kurume University School of Medicine, \\ Kurume, Fukuoka 830-0011; ${ }^{3}$ Division of Diabetes, Metabolism and Endocrinology, \\ Department of Medicine, Showa University School of Medicine, Tokyo 142-8666, Japan
}

Received May 21, 2021; Accepted June 14, 2021

DOI: $10.3892 / \mathrm{ol} .2021 .12890$

\begin{abstract}
Pigment epithelium-derived factor (PEDF) is one of the adipocytokines with multifaceted functions, which may serve a role in the development of various types of cardiometabolic disorders. Advanced glycation end products (AGEs) have been shown to contribute to numerous aging-associated disorders, such as cancer. However, it remains unclear whether and how PEDF exerts antitumor effects in AGE-exposed human breast cancer MCF-7 cells, and therefore this was explored in the present study. NADPH oxidase activity was measured with luciferase assay, while gene and protein expression levels were evaluated with quantitative PCR and western blot analysis, respectively. AGEs significantly increased NADPH oxidase-driven superoxide generation, cytochrome b-245 $\beta$ chain (gp91phox) and receptor for AGE (RAGE) mRNA expression, proliferation, mRNA and protein expression levels of vascular endothelial growth factor (VEGF), and matrix metalloproteinase (MMP)-9 mRNA expression in MCF-7 cells, all of which were dose-dependently inhibited by PEDF. Neutralizing antibody against laminin receptor (LR-Ab) significantly blocked these beneficial effects of PEDF in AGE-exposed MCF-7 cells. Furthermore, as in AGE-treated cells, PEDF dose-dependently inhibited the NADPH oxidase-driven superoxide generation, gp91phox, RAGE and MMP-9 mRNA expression, proliferation, mRNA and protein expression
\end{abstract}

Correspondence to: Dr Sho-Ichi Yamagishi, Division of Diabetes, Metabolism and Endocrinology, Department of Medicine, Showa University School of Medicine, 1-5-8 Hatanodai, Shinagawa-ku, Tokyo 142-8666, Japan

E-mail: shoichi@med.showa-u.ac.jp

Key words: advanced glycation end products, breast cancer, laminin receptor, pigment epithelium-derived factor, vascular endothelial growth factor levels of VEGF in non-treated control MCF-7 cells, and these effects were also reversed by LR-Ab. LR levels were not affected by the treatment with AGEs, PEDF or LR-Ab. The present study suggested that PEDF may exert antitumor effects in AGE-exposed breast cancer cells by suppressing NADPH oxidase-induced ROS generation and VEGF and MMP-9 expression via interaction with LR. Since PEDF expression is decreased in breast cancer tissues, pharmacological upregulation or restoration of PEDF may inhibit the growth and metastasis of breast cancer.

\section{Introduction}

Pigment epithelium-derived factor (PEDF), a serine protease inhibitor, is first identified from conditioned medium of retinal pigment epithelium and now recognized as one of the adipocytokines with multifaceted functions (1-11); it not only promotes neuronal cell differentiation, but also inhibits pathological angiogenesis and suppresses inflammatory and thrombotic reactions through its anti-oxidative properties in numerous cell culture and animal models (1-11). Moreover, we, along with others, have shown that decreased expression levels of PEDF in tumor tissues are associated with growth expansion, aggressiveness, and metastasis in various types of tumors, such as breast cancer and colorectal cancer, thereby being a poor prognostic marker in tumor-bearing patients (12-20). Since overexpression of PEDF or administration of PEDF-derived peptides have been shown to inhibit the growth and metastasis of a variety of tumors, including breast cancer in animal models, PEDF may be a novel therapeutic target for breast cancer (12-20).

Non-enzymatic modification of amino groups of proteins, lipids, and nucleic acids by sugars has progressed under diabetic conditions, which could alter their structural and functional properties via formation and accumulation of aging molecules called advanced glycation end products (AGEs) (21-25). Accumulating evidence has suggested the pathological involvement of AGEs in aging-related diseases, such as cancer, cardiovascular disease, diabetes, osteoporosis, Alzheimer's 
disease (21-25). Indeed, we have previously found that AGEs stimulate proliferation and gene expression of vascular endothelial growth factor (VEGF) in MCF-7 human breast cancer cells, which may contribute to the tumor expansion and metastasis (26). Although PEDF exerted anti-angiogenic effects on endothelial cells through the interaction of a non-integrin laminin receptor (LR) (11), it remains unclear whether and how PEDF could inhibit the AGE-induced growth and VEGF expression in MCF-7 breast cancer cells. In this study, we addressed the issue.

\section{Materials and methods}

Materials. Dulbecco's modified Eagle's medium (DMEM) and MCF-7 human breast cancer cells were obtained from Sigma-Aldrich; Merck KGaA and American Type Culture Collection, respectively. Neutralizing monoclonal antibody (Ab) raised against LR (clone MLuC5; LR-Ab) was purchased from Abcam (cat. no. ab3099). Normal mouse IgG was purchased from WAKO Pure Chemical Co. (cat. no. 140-09511).

Preparation of PEDF proteins. PEDF proteins were purified as described previously (27). SDS-PAGE analysis of purified PEDF proteins revealed a single band with a molecular mass of about $50-\mathrm{kDa}$, which showed positive reactivity with monoclonal Ab raised against human PEDF (TransGenic Inc.; cat. no. KM037).

Preparation of AGEs. AGEs were prepared as described previously (28). In brief, BSA (25 $\mathrm{mg} / \mathrm{ml})$ was incubated under sterile conditions with $0.1 \mathrm{M}$ glyceraldehyde in $0.2 \mathrm{M}$ $\mathrm{NaPO}_{4}$ buffer ( $\mathrm{pH}$ 7.4) for 7 days. Then unincorporated sugars were removed by PD-10 column chromatography and dialysis against phosphate-buffered saline. Control non-glycated BSA was incubated in the same conditions except for the absence of reducing sugars.

Cells. MCF-7 cells were maintained in DMEM supplemented with $10 \%$ heat-inactivated fetal bovine serum. MCF-7 cells were treated with or without $100 \mu \mathrm{g} / \mathrm{ml}$ non-glycated BSA or AGE-modified BSA (AGEs) in the presence or absence of the indicated concentrations of PEDF, $5 \mu \mathrm{g} / \mathrm{ml} \mathrm{LR}-\mathrm{Ab}$, or $5 \mu \mathrm{g} / \mathrm{ml}$ mouse $\mathrm{IgG}$ in DMEM with $1 \%$ fetal bovine serum for $24 \mathrm{~h}$.

NADPH oxidase activity. NADPH oxidase activity of MCF-7 cells was measured by luminescence assay as described previously (6).

Reactive oxygen species (ROS) generation. Intracellular ROS production in MCF-7 cells was measured with a fluorescent probe, 5-(and-6)-carboxy-2',7'-difluorodihydrofluorescein diacetate (carboxy-H $\mathrm{H}_{2}$ DFFDA) purchased from Thermo Fisher Scientific (29).

Real-time reverse transcription-polymerase chain reaction $(R T-P C R)$. Total RNA was extracted from cells with NucleoSpin RNA Plus (Takara Bio Inc.) according to the manufacturer's instructions. cDNA was obtained using the
PrimeScript RT reagent kit (Takara Bio, Inc.). Quantitative real-time RT-PCR was performed using Assay-on-Demand and TaqMan 5 fluorogenic nuclease chemistry (Applied Biosystems) according to the supplier's recommendation. IDs of primers for human cytochrome b-245 $\alpha$ chain (p22phox), cytochrome b-245 $\beta$ chain (gp91phox), receptor for AGE (RAGE), VEGF, matrix metalloproteinase-9 (MMP-9) and $\beta$-actin gene were Hs00609145_m1, Hs00166163_m1, Hs00542592_g1, Hs00900055_m1, Hs00234579_m1 and Hs99999903_m1 respectively. Expression levels of RAGE, VEGF, MMP-9 and $\beta$-actin were measured using the $2^{-\Delta \Delta \mathrm{Cq}}$ method. Data were normalized by the intensity of internal control $\beta$-actin-derived signals. $\Delta \mathrm{Cq}$ and $\Delta \Delta \mathrm{Cq}$ values were calculated using the following mathematical formulas: $\Delta \mathrm{Cq}=\mathrm{Cq}(\mathrm{p} 22 \mathrm{phox} /$ gp91phox/RAGE/VEGF/MMP-9)-Cq( $\beta$-actin), and $\Delta \Delta \mathrm{Cq}=\Delta \mathrm{Cq}$ (target sample) $-\Delta \mathrm{Cq}$ (control sample).

Cell proliferation. Cell proliferation was measured with a Cell Proliferation Reagent WST-1 by measuring the absorbance at wavelength $450 \mathrm{~nm}$ according to the supplier's recommendations (Darmstadt, Germany).

Measurements of VEGF. VEGF levels in MCF-7 cell culture medium were measured with an enzyme-linked immunosorbent assay kit (Proteintech Group, Inc.).

Western blot analysis. Proteins were extracted from MCF-7 cells using lysis buffer (27). The samples were then separated by SDS-PAGE and transferred to nitrocellulose membranes (Life Technologies Japan, Ltd.). Membranes were probed with LR-Ab (1:100 dilution; Santa Cruz Biotechnology, Inc.; cat. no. sc-20979) for $12 \mathrm{~h}$ at room temperature, and then incubated with peroxidase-conjugated polyclonal donkey anti-rabbit IgG Ab (1:20,000 dilution; GE Healthcare UK Ltd.; cat. no. NA934-100UL). Tubulin was visualized with peroxidase-conjugated anti- $\alpha$-tubulin antibody (1:10,000 dilution; Abcam; cat. no. ab40742). Immune complexes were visualized using an enhanced chemiluminescence detection system (Amersham Bioscience). Protein signals were quantified using ImageJ software (version 1.53; National Institutes of Health, Bethesda, MD, USA). Expression levels of LR were normalized by those of $\alpha$-tubulin.

Statistical analysis. All values were presented as mean \pm standard deviation. Post hoc comparison of means was carried out using Tukey's honestly significant difference test after one-way ANOVA by R software (version 4.0.3. The R Foundation for Statistical Computing Platform). $\mathrm{P}<0.05$ was considered significant.

\section{Results}

We first examined the effects of PEDF on NADPH oxidase activity, mRNA levels of p22phox and gp91phox, two membrane components of NADPH oxidase, ROS generation, and RAGE gene expression in AGE-exposed MCF-7 cells. As shown in Fig. 1A-C, compared with non-glycated BSA, AGE-modified BSA (AGEs) significantly increased NADPH oxidase activity, gp91phox mRNA levels, and ROS generation in MCF-7 cells, all of which were dose-dependently inhibited by the treatment 
with PEDF. Furthermore, the inhibitory effects of $100 \mathrm{nM}$ PEDF on NADPH oxidase activity, gp91phox mRNA levels, and ROS generation in AGE-exposed MCF-7 cells were significantly blocked by LR-Ab (Fig. 1D-F). As is the case in NADPH oxidase activity, gp91phox mRNA levels, and ROS generation, PEDF at $100 \mathrm{nM}$ significantly suppressed the AGE-induced up-regulation of RAGE mRNA level in MCF-7 cells, which was also inhibited by LR-Ab (Fig. 1G and H). LR-Ab alone did not affect NADPH oxidase activity, mRNA levels of p22phox and gp91phox, ROS generation, or RAGE gene expression in non-glycated BSA-exposed MCF-7 cells.

AGEs significantly stimulated proliferation of MCF-7 cells, which was suppressed by PEDF in a dose-dependent manner (Fig. 1I). LR-Ab blocked the growth inhibitory effects of $100 \mathrm{nM}$ PEDF in AGE-exposed MCF-7 cells (Fig. 1J). Although western blot analysis revealed that LR was actually expressed in MCF-7 cells, expression levels of LR were not changed by the treatment of AGEs, $100 \mathrm{nM}$ PEDF, or LR-Ab (Fig. 1K). We have already confirmed that PEDF directly binds to LR, which is significantly blocked by LR-Ab (27).

We next examined the effects of PEDF on VEGF and MMP-9 expression in AGE-exposed MCF-7 cells. As shown in Fig. 2A and B, VEGF gene and protein expression were significantly stimulated by AGEs, which were inhibited by PEDF in a dose-dependently manner. LR-Ab significantly blocked the effects of PEDF in VEGF expression in MCF-7 cells exposed to AGEs (Fig. 2C and D). Furthermore, PEDF dose-dependently inhibited the AGE-induced increase in MMP-9 gene expression in MCF-7 cells (Fig. 2E). LR-Ab also significantly blocked the PEDF-induced MMP-9 gene suppression in AGE-exposed MCF-7 cells (Fig. 2F).

We further investigated the effects of PEDF in NADPH oxidase activity, mRNA levels of p22phox and gp91phox, ROS generation, RAGE, VEGF, and MMP-9 expression, and proliferation in MCF-7 cells not exposed to BSA or AGEs. As is the case in non-glycated BSA- or AGE-exposed MCF-7 cells, PEDF dose-dependently inhibited the NADPH oxidase activity, gp91phox mRNA levels, ROS generation, RAGE mRNA levels, proliferation, VEGF gene and protein expression, and MMP-9 mRNA levels in MCF-7 cells (Figs. 3, 4A, B and E). LR-Ab significantly blocked all these effects of $100 \mathrm{nM}$ PEDF in MCF-7 cells (Figs. 3 and 4C, D and F). LR expression levels were not affected by PEDF or LR-Ab (Fig. 4G).

\section{Discussion}

Breast cancer is the most common cancer in women all over the world, accounting for $10-15 \%$ of all cancer deaths in developed countries $(30,31)$. There is a growing body of evidence to show the clinical link between diabetes and breast cancer $(20,32,33)$. Diabetes is associated with the higher incidence and more advanced stage of breast cancer, thereby increasing the mortality rate in these patients compared with non-diabetic individuals $(32,33)$. Moreover, we, along with others, have shown the pathological role of AGEs, which are formed during a physiological aging process and at an accelerated rate under diabetic conditions, in the development and progression of breast cancer (34-37). Indeed, AGEs have been reported to stimulate proliferation, migration, invasion, and VEGF gene expression in cultured human breast cancer cells in association with tamoxifen resistance (26). Moreover, dietary intake of AGEs is associated with the increased risk of breast cancer in two independent cohort studies $(38,39)$. These are reasons why we focused on the effects of PEDF on AGE-exposed human breast cancer cells.

In the present study, we found that AGEs significantly increased NADPH oxidase activity, gp91phox mRNA levels, ROS generation, RAGE gene expression, proliferation, gene and protein expression of VEGF, and MMP-9 mRNA levels in cultured breast cancer cells, all of which were dose-dependently inhibited by the treatment with PEDF. Furthermore, these beneficial effects of PEDF on AGE-exposed MCF-7 breast cancer cells were significantly blocked by neutralizing LR-Ab. In addition, PEDF exerted similar anti-tumor effects in non-glycated BSA- or AGE-exposed MCF-7 cells, whose actions were also inhibited by LR-Ab. VEGF and MMP-9 are crucial factors for tumor growth and invasion, respectively, whose expression levels are associated with breast cancer progression and metastasis (40-42). Given that PEDF expression levels are decreased in breast cancer tissues $(15,20)$, our present study suggests that pharmacological up-regulation or restoration of PEDF may inhibit the growth and metastasis of breast cancer via the interaction with LR in two distinct pathways; one is a direct inhibition of tumor growth, and the other is the suppression of VEGF and MMP-9 expression, which could lead to attenuate tumor angiogenesis, invasion, and metastasis.

We have previously shown that AGEs stimulate growth and VEGF expression in both endothelial cells and malignant melanoma cells by inducing the ROS generation through the interaction with RAGE $(29,43)$. Oxidative stress and redox-sensitive transcriptional factor are involved in VEGF and MMP-9 gene expression in various kinds of cells, including tumor cells $(29,43-46)$. Moreover, p66ShcA has recently been shown to play a role in breast cancer metastasis, while quercetin, an anti-oxidant suppresses the mobility as well as VEGF and MMP-9 expression of breast cancer cells $(47,48)$. Since PEDF has been reported to attenuate the AGE-RAGE-induced proliferative, inflammatory and thrombotic reactions in a variety of cells and tissues through the suppression of NADPH oxidase-driven superoxide generation $(6,11)$, the present findings suggest that PEDF may exert anti-tumor effects on AGE-exposed breast cancer cells by suppressing the NADPH oxidase-induced ROS generation via interaction with LR via down-regulation of gp91phox mRNA levels. In support of our speculation, we have found previously that (1) LR-Ab actually inhibits the binding of PEDF to LR and resultantly restores VEGF mRNA levels in PEDF-exposed myeloma cells and (2) PEDF inhibits tumor necrosis factor- $\alpha$-induced inflammatory reactions in endothelial cells via inhibition of NADPH oxidase activity through the interaction of $c a .60-\mathrm{kDa}$ receptor, which is considered to be LR $(16,49)$. Taken together, although the anti-tumorigenic ability and the anti-invasiveness are different aspects, suppression of oxidative stress by PEDF may connect these two phenomena. We did not know the exact reason why our present results contradicted the effect of PEDF in hepatocellular carcinoma cells; PEDF was found to play a role in metastasis and angiogenesis in this cell type (50). However, there is accumulating evidence that decreased expression levels 

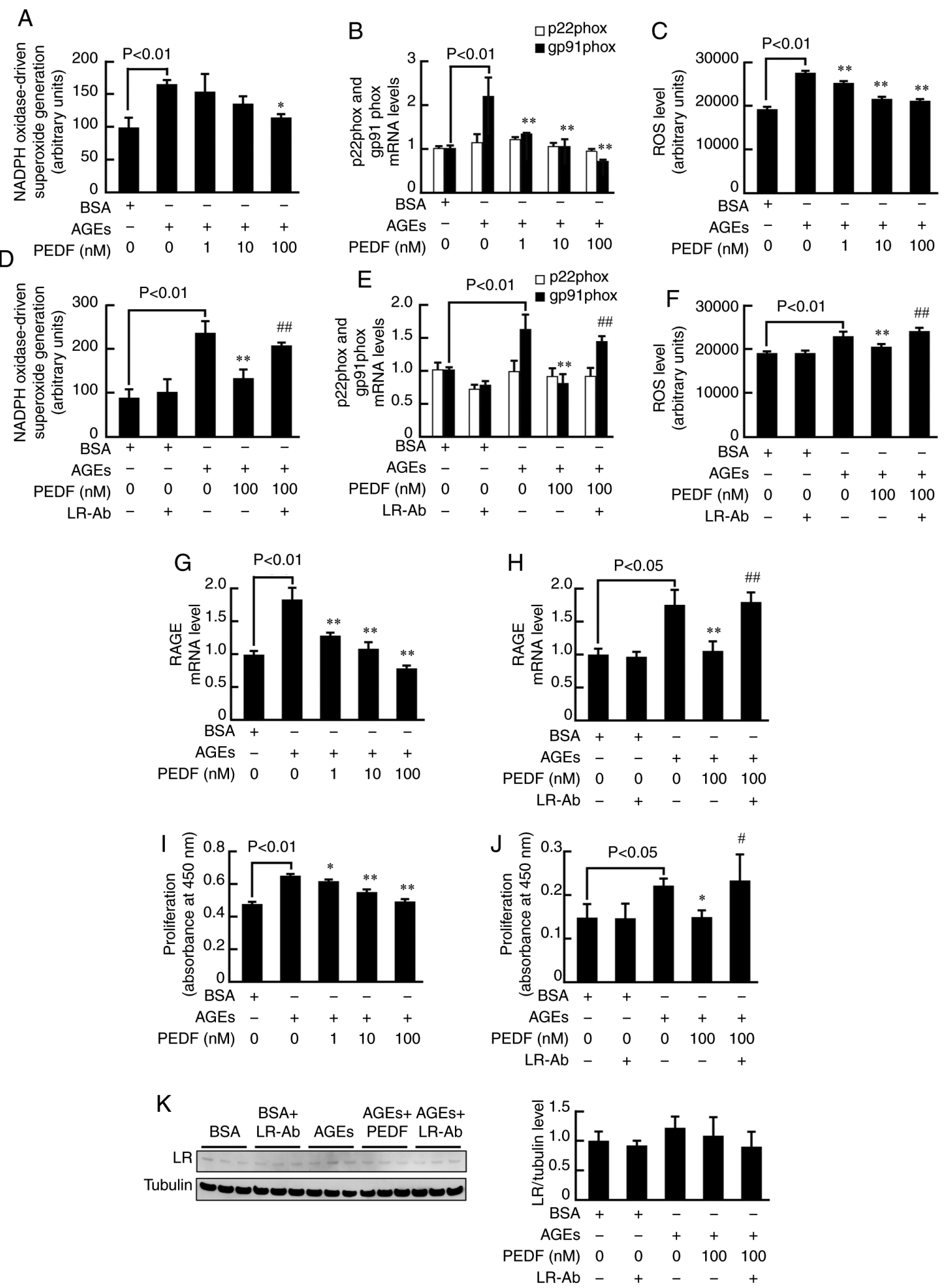

Figure 1. Effects of PEDF on NADPH oxidase-driven superoxide generation, mRNA expression levels of p22phox and gp91phox, ROS production, RAGE mRNA expression, proliferation and LR expression in MCF-7 breast cancer cells exposed to AGEs or BSA. (A) NADPH oxidase-driven superoxide generation $(\mathrm{n}=4)$, (B) mRNA expression levels of p22phox and gp91phox (n=3), and (C) ROS production ( $\mathrm{n}=4)$ in MCF-7 cells treated with $100 \mu \mathrm{g} / \mathrm{ml}$ non-glycated BSA or AGEs in the presence or absence of the indicated concentrations of PEDF. (D) NADPH oxidase-driven superoxide generation $(n=4)$, (E) mRNA expression levels of p22phox and gp91phox ( $\mathrm{n}=3$ ), and (F) ROS production ( $\mathrm{n}=4)$ in MCF-7 cells treated with $100 \mu \mathrm{g} / \mathrm{ml}$ non-glycated BSA or AGEs in the presence or absence of the indicated concentrations of PEDF or $5 \mu \mathrm{g} / \mathrm{ml}$ LR-Ab. (G) RAGE mRNA expression in MCF-7 cells treated with $100 \mu \mathrm{g} / \mathrm{ml}$ non-glycated BSA or AGEs in the presence or absence of the indicated concentrations of PEDF or (H) $5 \mu \mathrm{g} / \mathrm{ml}$ LR-Ab (n=3). (I) Proliferation of MCF-7 cells treated with $100 \mu \mathrm{g} / \mathrm{ml}$ non-glycated BSA or AGEs in the presence or absence of the indicated concentrations of PEDF or (J) $5 \mu \mathrm{g} / \mathrm{ml} \mathrm{LR}-\mathrm{Ab}(\mathrm{n}=4)$. (K) LR protein expression in MCF-7 cells treated with $100 \mu \mathrm{g} / \mathrm{ml}$ non-glycated BSA or AGEs in the presence or absence of the indicated concentrations of PEDF or $5 \mu \mathrm{g} / \mathrm{ml}$ LR-Ab analyzed by western blotting $(\mathrm{n}=3)$. ${ }^{*} \mathrm{P}<0.05$ and ${ }^{* *} \mathrm{P}<0.01$ vs. AGEs; ${ }^{*} \mathrm{P}<0.05$ and ${ }^{\# \#} \mathrm{P}<0.01$ vs. AGEs and $100 \mathrm{nM}$ PEDF. AGEs, advanced glycation end products; LR, laminin receptor; Ab, antibody; PEDF, pigment epithelium-derived factor; ROS, reactive oxygen species; BSA, bovine serum albumin; p22phox, cytochrome b-245 $\alpha$ chain; gp91phox, cytochrome b-245 $\beta$ chain; RAGE, receptor for AGE. 
A

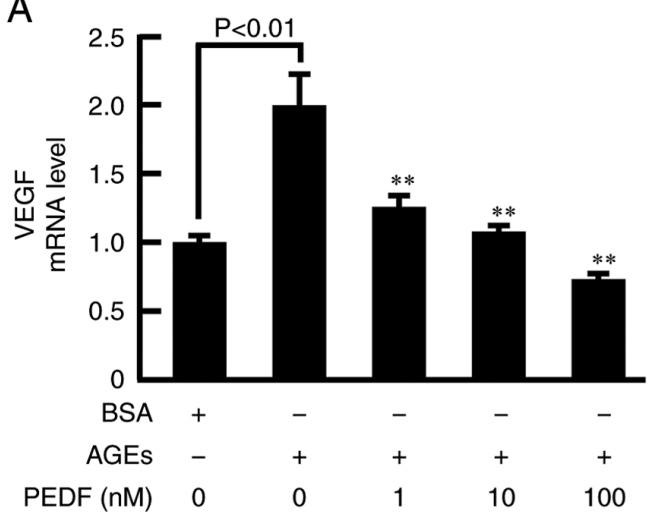

C

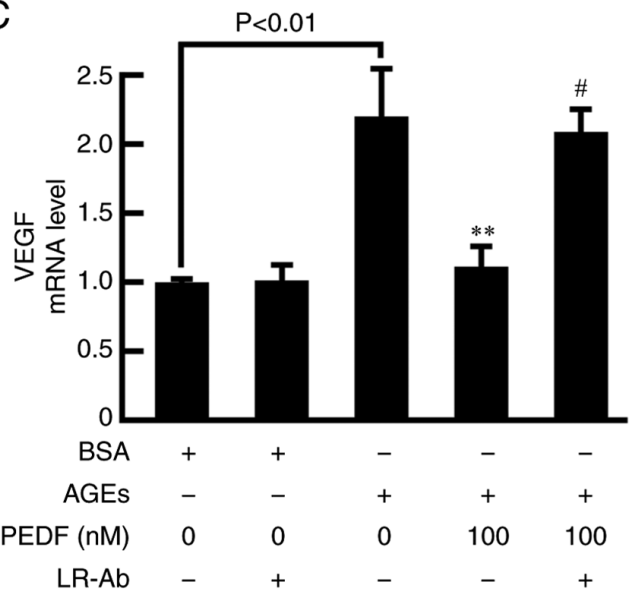

E

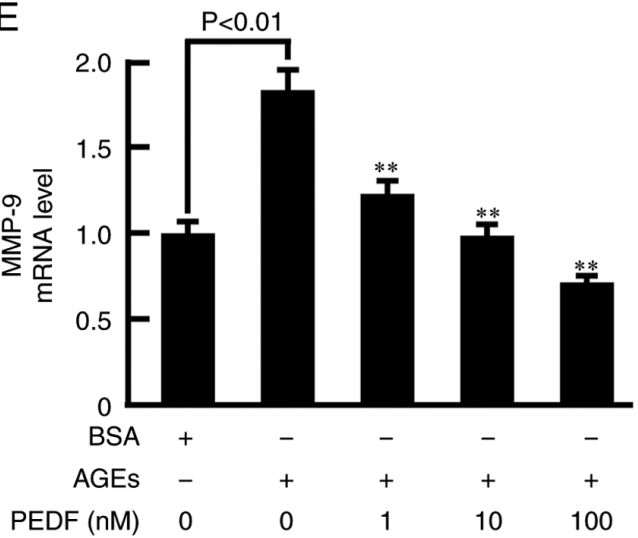

B

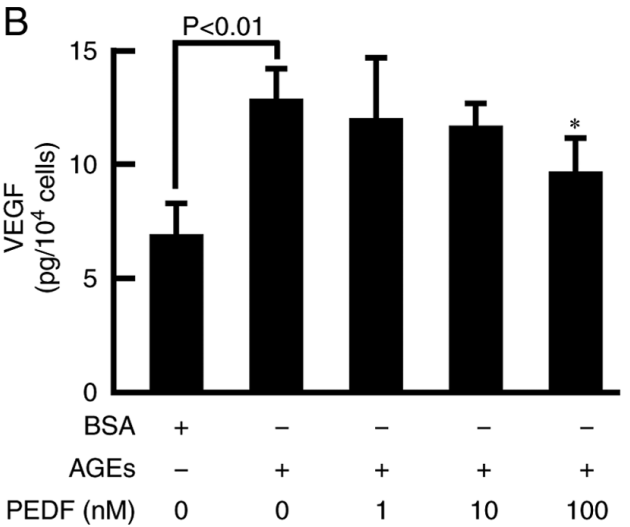

D

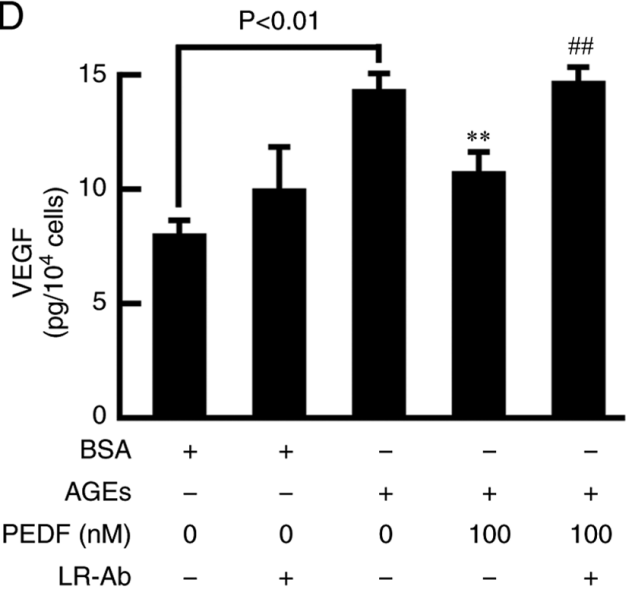

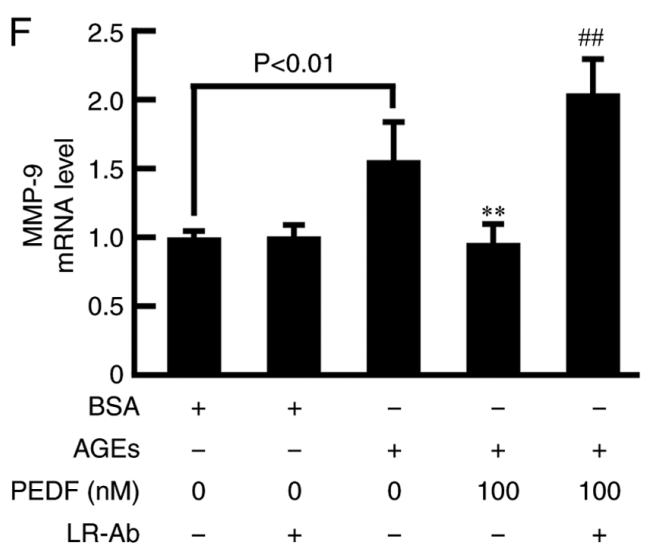

Figure 2. Effects of PEDF on VEGF mRNA and protein expression, and MMP-9 mRNA expression in breast cancer MCF-7 cells exposed to AGEs or BSA. $\operatorname{VEGF}(\mathrm{A})$ mRNA $(\mathrm{n}=3)$ and $(\mathrm{B})$ protein expression $(\mathrm{n}=4)$ in MCF-7 cells treated with $100 \mu \mathrm{g} / \mathrm{ml}$ non-glycated BSA or AGEs in the presence or absence of the indicated concentrations of PEDF. VEGF (C) mRNA ( $\mathrm{n}=3$ ) and (D) protein expression (n=4) in MCF-7 cells treated with $100 \mu \mathrm{g} / \mathrm{ml}$ non-glycated BSA or AGEs in the presence or absence of the indicated concentrations of PEDF or $5 \mu \mathrm{g} / \mathrm{ml} \mathrm{LR}-\mathrm{Ab}$. (E) MMP-9 mRNA expression in MCF-7 cells treated with $100 \mu \mathrm{g} / \mathrm{ml}$ non-glycated BSA or AGEs in the presence or absence of the indicated concentrations of PEDF or (F) $5 \mu \mathrm{g} / \mathrm{ml} \mathrm{LR}-\mathrm{Ab}(\mathrm{n}=3)$. ${ }^{*} \mathrm{P}<0.05 \mathrm{and}$ ${ }^{* *} \mathrm{P}<0.01$ vs. AGEs; ${ }^{\#} \mathrm{P}<0.05$ and ${ }^{\# \#} \mathrm{P}<0.01$ vs. AGEs and $100 \mathrm{nM}$ PEDF. AGEs, advanced glycation end products; LR, laminin receptor; Ab, antibody; PEDF, pigment epithelium-derived factor; VEGF, vascular endothelial growth factor; MMP-9, matrix metalloproteinase 9; BSA, bovine serum albumin.

of PEDF are associated with angiogenesis and metastasis in various types of tumors, whereas PEDF inhibits the growth and metastasis of tumors in animal models (12-20). Differences in expression levels or pattern of PEDF and LR between breast cancer cells and hepatocellular carcinoma cells may partly explain the discrepant results.

Results of all the parameters we examined here were almost the same regardless of whether the cells were treated with AGEs or not. Therefore, AGEs may not affect the anti-tumor effects of PEDF. However, AGEs have been shown to decrease PEDF expression in endothelial cells, mesangial cells, and podocytes via oxidative stress generation, further potentiating the deleterious effects by attenuating the protective action of PEDF against AGEs (51-53). Therefore, there is a bi-directional interaction between AGEs and PEDF. In many aging-related diseases, such as cancer and diabetic vascular complications, the balance may shift towards AGEs. Amelioration of the balance of two molecules may be a novel therapeutic strategy 
A

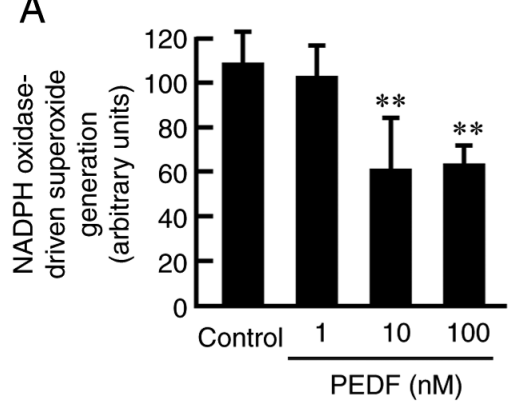

D

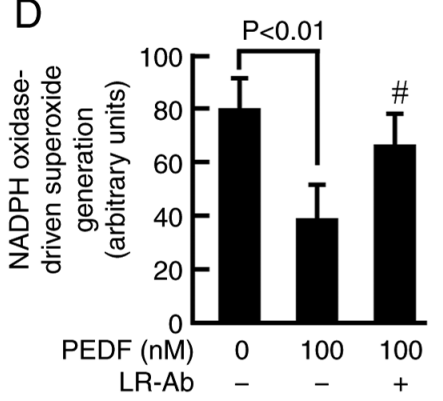

B $\square$ p22phox

- gp91phox
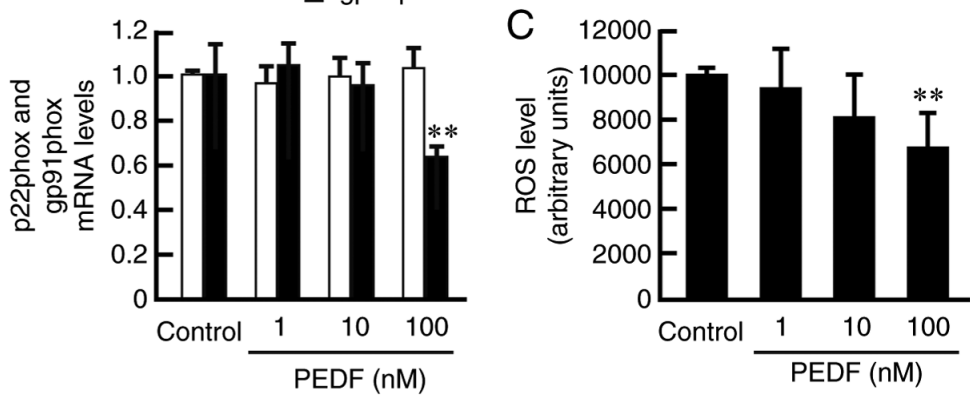

E

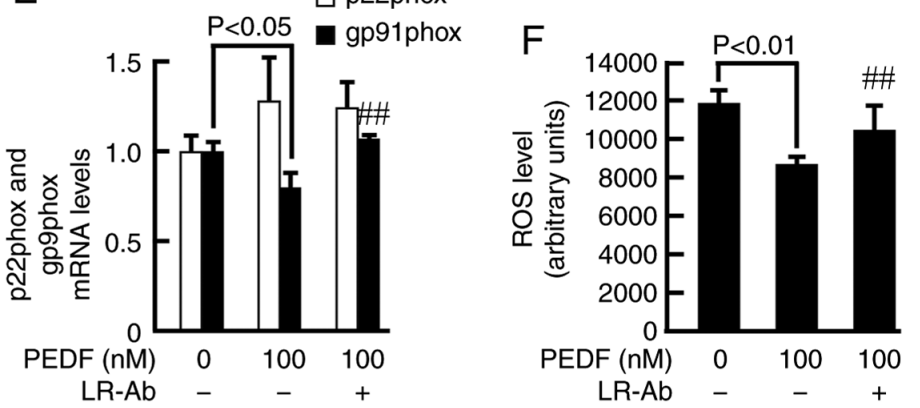

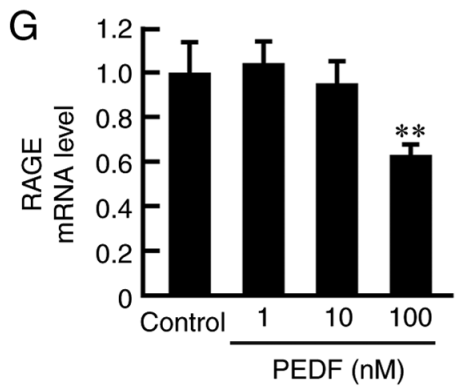

$\mathrm{H}$
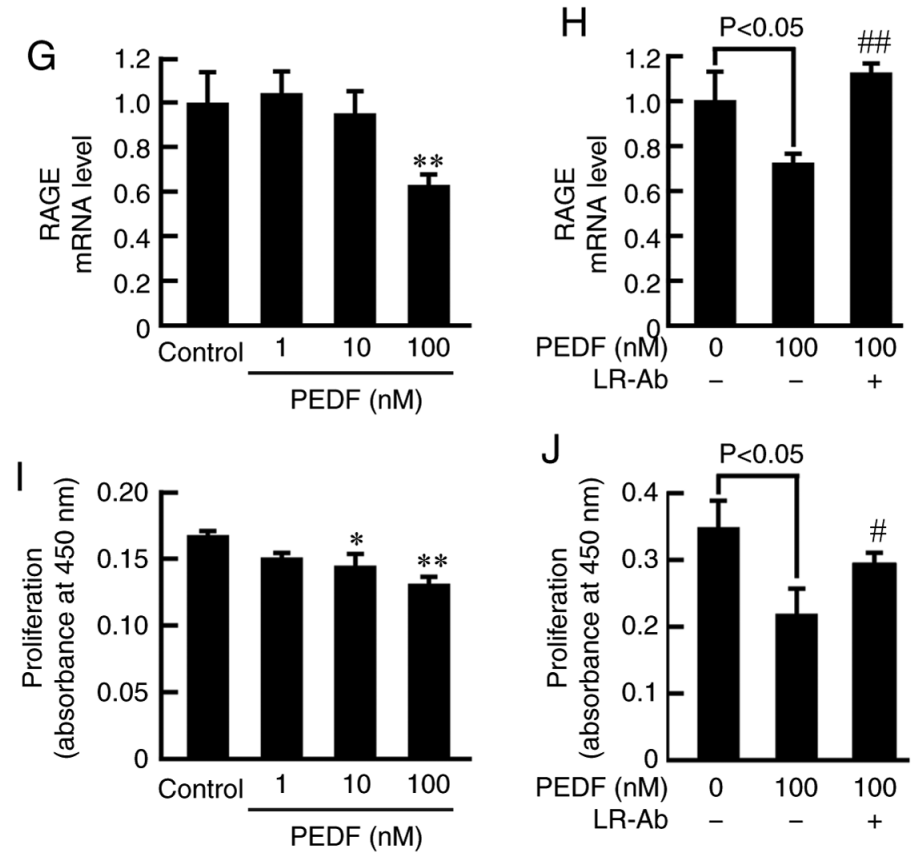

Figure 3. Effects of PEDF on NADPH oxidase-driven superoxide generation, mRNA expression levels of p22phox and gp91phox, ROS production, RAGE mRNA expression and proliferation in MCF-7 breast cancer cells. (A) NADPH oxidase-driven superoxide generation (n=4), (B) mRNA expression levels of p22phox and gp91phox ( $n=3)$, and (C) ROS production $(n=4)$ in MCF-7 cells treated with the indicated concentrations of PEDF. (D) NADPH oxidase-driven superoxide generation ( $\mathrm{n}=4)$, (E) mRNA expression levels of p22phox and gp91phox $(\mathrm{n}=3)$, and (F) ROS production ( $\mathrm{n}=4)$ in MCF-7 cells treated with the indicated concentrations of PEDF in the presence or absence of $5 \mu \mathrm{g} / \mathrm{ml} \mathrm{LR}-\mathrm{Ab}$. (G and $\mathrm{H}$ ) RAGE mRNA expression in MCF-7 cells treated with the indicated concentrations of PEDF in the presence or absence of $5 \mu \mathrm{g} / \mathrm{ml} \mathrm{LR}-\mathrm{Ab}(\mathrm{n}=3)$. (I and J) Proliferation of MCF-7 cells treated with the indicated concentrations of PEDF in the presence or absence of $5 \mu \mathrm{g} / \mathrm{ml}$ LR-Ab $(\mathrm{n}=4) .{ }^{*} \mathrm{P}<0.05$ and ${ }^{* *} \mathrm{P}<0.01 \mathrm{vs}$. control; ${ }^{\#} \mathrm{P}<0.05$ and ${ }^{\# \#} \mathrm{P}<0.01 \mathrm{vs} .100 \mathrm{nM} \mathrm{PEDF}$. AGEs, advanced glycation end products; LR, laminin receptor; Ab, antibody; PEDF, pigment epithelium-derived factor; ROS, reactive oxygen species; p22phox, cytochrome b-245 $\alpha$ chain; gp91phox, cytochrome b-245 $\beta$ chain; RAGE, receptor for AGE.

for aging-related diseases, including breast cancer in patients with diabetes.

\section{Acknowledgements}

Not applicable.

\section{Funding}

The present study was supported in part by Grants-in-Aid for Scientific Research (grant nos. 20K06475 and 19K06461) from the Ministry of Education, Culture, Sports, Science and Technology, Japan. 

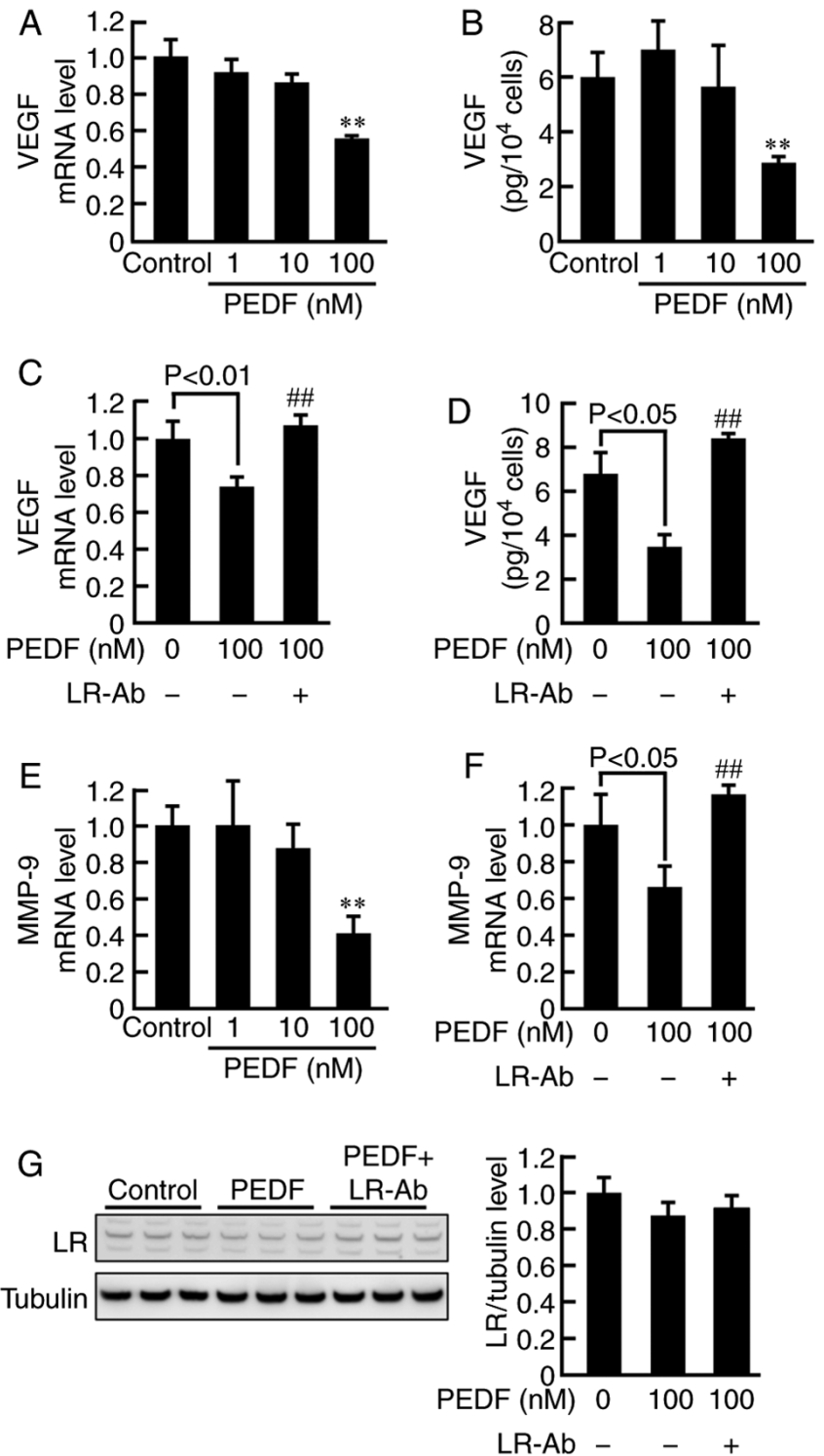

Figure 4. Effects of PEDF on VEGF mRNA and protein expression, MMP-9 mRNA expression and LR protein expression in MCF-7 breast cancer cells. $\operatorname{VEGF}(A)$ mRNA $(n=3)$ and $(B)$ protein expression $(n=4)$ in MCF-7 cells treated with the indicated concentrations of PEDF. VEGF (C) mRNA ( $n=3)$ and (D) protein expression $(n=4)$ in $M C F-7$ cells treated with the indicated concentrations of PEDF in the presence or absence of $5 \mu \mathrm{g} / \mathrm{ml} \mathrm{LR}-\mathrm{Ab}$ (E and F) MMP-9 mRNA expression in MCF-7 cells treated with the indicated concentrations of PEDF in the presence or absence of $5 \mu \mathrm{g} / \mathrm{ml} \mathrm{LR}-\mathrm{Ab}$ $(n=3)$. $(G)$ LR protein expression in MCF-7 cells treated with the indicated concentrations of PEDF in the presence or absence of $5 \mu \mathrm{g} / \mathrm{ml} \mathrm{LR}-\mathrm{Ab}$ analyzed by western blotting $(\mathrm{n}=3) .{ }^{* *} \mathrm{P}<0.01$ vs. control; ${ }^{\# \#} \mathrm{P}<0.01$ vs. $100 \mathrm{nM}$ PEDF. AGEs, advanced glycation end products; LR, laminin receptor; $\mathrm{Ab}$, antibody; PEDF, pigment epithelium-derived factor; VEGF, vascular endothelial growth factor; MMP-9, matrix metalloproteinase 9.

\section{Availability of data and materials}

The datasets used and/or analyzed during the current study are available from the corresponding author on reasonable request.

\section{Authors' contributions}

SIY conceptualized and designed the study, acquired, analyzed and interpreted the data, drafted the manuscript and takes responsibility for all the integrity of the data and accuracy of the data analysis. ST, TM, YK, AS and MY conceptualized and designed the study, as well as acquired, analyzed and interpreted the data. MY revised the manuscript critically for intellectual content. ST and TM confirm the authenticity of all the raw data. All authors read and approved the final manuscript.

\section{Ethics approval and consent to participate}

Not applicable.

\section{Patient consent for publication}

Not applicable.

\section{Competing interests}

The authors declare that they have no competing interests.

\section{References}

1. Tombran-Tink J, Chader CG and Johnson LV: PEDF: A pigment epithelium-derived factor with potent neuronal differentiative activity. Exp Eye Res 53: 411-414, 1991.

2. Dawson DW, Volpert OV, Gillis P, Crawford SE, Xu H, Benedict W and Bouck NP: Pigment epithelium-derived factor: A potent inhibitor of angiogenesis. Science 285: 245-248, 1999.

3. Duh EJ, Yang HS, Suzuma I, Miyagi M, Youngman E, Mori K, Katai M, Yan L, Suzuma K, West K, et al: Pigment epithelium-derived factor suppresses ischemia-induced retinal neovascularization and VEGF-induced migration and growth. Invest Ophthalmol Vis Sci 43: 821-829, 2002.

4. Yamagishi S, Amano S, Inagaki Y, Okamoto T, Takeuchi M and Inoue $\mathrm{H}$ : Pigment epithelium-derived factor inhibits leptin-induced angiogenesis by suppressing vascular endothelial growth factor gene expression through anti-oxidative properties. Microvasc Res 65: 186-190, 2003.

5. Doll JA, Stellmach VM, Bouck NP, Bergh AR, Lee C, Abramson LP, Cornwell ML, Pins MR, Borensztajn J and Crawford SE: Pigment epithelium-derived factor regulates the vasculature and mass of the prostate and pancreas. Nat Med 9: 774-780, 2003

6. Yamagishi S, Nakamura K, Matsui T, Inagaki Y, Takenaka K, Jinnouchi Y, Yoshida Y, Matsuura T, Narama I, Motomiya Y, et al: Pigment epithelium-derived factor inhibits advanced glycation end product-induced retinal vascular hyperpermeability by blocking reactive oxygen species-mediated vascular endothelial growth factor expression. J Biol Chem 281: 20213-20220, 2006.

7. Fujimura T, Yamagishi S, Ueda S, Fukami K, Shibata R, Matsumoto Y, Kaida Y, Hayashida A, Koike K, Matsui T, et al: Administration of pigment epithelium-derived factor (PEDF) reduces proteinuria by suppressing decreased nephrin and increased VEGF expression in the glomeruli of adriamycin-injected rats. Nephrol Dial Transplant 24: 1397-1406, 2009.

8. Matsui T, Higashimoto Y, Taira J and Yamagishi S: Pigment epithelium-derived factor (PEDF) binds to caveolin-1 and inhibits the pro-inflammatory effects of caveolin-1 in endothelial cells. Biochem Biophys Res Commun 441: 405-410, 2013.

9. Matsui T, Nishino Y, Ojima A, Maeda S, Tahara N and Yamagishi S: Pigment epithelium-derived factor improves metabolic derangements and ameliorates dysregulation of adipocytokines in obese type 2 diabetic rats. Am J Pathol 184: 1094-1103, 2014

10. Takenaka K, Yamagishi S, Matsui T, Nakamura K, Jinnouchi Y, Yoshida Y, Ueda S, Katsuki Y, Katsuda Y and Imaizumi T: Pigment epithelium-derived factor (PEDF) administration inhibits occlusive thrombus formation in rats: A possible participation of reduced intraplatelet PEDF in thrombosis of acute coronary syndromes. Atherosclerosis 197: 25-33, 2008.

11. Yamagishi SI and Matsui T: Pigment epithelium-derived factor: A novel therapeutic target for cardiometabolic diseases and related complications. Curr Med Chem 25: 1480-1500, 2018. 
12. Abe R, Shimizu T, Yamagishi S, Shibaki A, Amano S, Inagaki Y, Watanabe H, Sugawara H, Nakamura H, Takeuchi M, et al: Overexpression of pigment epithelium-derived factor decreases angiogenesis and inhibits the growth of human malignant melanoma cells in vivo. Am J Pathol 164: 1225-1232, 2004.

13. Takenaka K, Yamagishi S, Jinnouchi Y, Nakamura K, Matsui T and Imaizumi T: Pigment epithelium-derived factor (PEDF)-induced apoptosis and inhibition of vascular endothelial growth factor (VEGF) expression in MG63 human osteosarcoma cells. Life Sci 77: 3231-3241, 2005.

14. Mirochnik Y, Aurora A, Schulze-Hoepfner FT, Deabes A, Shifrin V, Beckmann R, Polsky C and Volpert OV: Short pigment epithelial-derived factor-derived peptide inhibits angiogenesis and tumor growth. Clin Cancer Res 15: 1655-1663, 2009.

15. Zhou D, Cheng SQ, Ji HF, Wang JS, Xu HT, Zhang GQ and Pang D: Evaluation of protein pigment epithelium-derived factor (PEDF) and microvessel density (MVD) as prognostic indicators in breast cancer. J Cancer Res Clin Oncol 136: 1719-1727, 2010

16. Seki R, Yamagishi S, Matsui T, Yoshida T, Torimura T, Ueno T, Sata $M$ and Okamura T: Pigment epithelium-derived factor (PEDF) inhibits survival and proliferation of VEGF-exposed multiple myeloma cells through its anti-oxidative properties. Biochem Biophys Res Commun 431: 693-697, 2013.

17. Becerra SP and Notario V: The effects of PEDF on cancer biology: Mechanisms of action and therapeutic potential. Nat Rev Cancer 13: 258-271, 2013.

18. Gong Q, Qiu S, Li S, Ma Y, Chen M, Yao Y, Che D, Feng J, Cai W, Ma J, et al: Proapoptotic PEDF functional peptides inhibit prostate tumor growth-a mechanistic study. Biochem Pharmacol 92: 425-437, 2014.

19. Zhou D, Zhang M, Xu P, Yu Y, Ye G, Zhang L and Wu A: Expression of pigment epithelium-derived factor is associated with a good prognosis and is correlated with epithelial-mesenchymal transition-related genes in infiltrating ductal breast carcinoma. Oncol Lett 11: 116-124, 2016.

20. Yamagishi SI, Koga Y, Sotokawauchi A, Hashizume N, Fukahori S, Matsui T and Yagi M: Therapeutic potential of pigment epithelium-derived factor in cancer. Curr Pharm Des 25: 313-324, 2019.

21. Yamagishi S: Potential clinical utility of advanced glycation end product cross-link breakers in age- and diabetes-associated disorders. Rejuvenation Res 15: 564-572, 2012.

22. Sadowska-Bartosz I and Bartosz G: Effect of glycation inhibitors on aging and age-related diseases. Mech Ageing Dev 160: $1-18,2016$

23. Rowan S, Bejarano E and Taylor A: Mechanistic targeting of advanced glycation end-products in age-related diseases. Biochim Biophys Acta Mol Basis Dis 1864: 3631-3643, 2018.

24. Yamagishi SI and Matsui T: Therapeutic potential of DNA-aptamers raised against AGE-RAGE axis in diabetes-related complications. Curr Pharm Des 24: 2802-2809, 2018.

25. Rungratanawanich W, Qu Y, Wang X, Essa MM and Song BJ: Advanced glycation end products (AGEs) and other adducts in aging-related diseases and alcohol-mediated tissue injury. Exp Mol Med 53: 168-188, 2021.

26. Ishibashi Y, Matsui T, Takeuchi M and Yamagishi S: Metformin inhibits advanced glycation end products (AGEs)-induced growth and VEGF expression in MCF-7 breast cancer cells by suppressing AGEs receptor expression via AMP-activated protein kinase. Horm Metab Res 45: 387-390, 2013.

27. Matsui T, Higashimoto Y and Yamagishi S: Laminin receptor mediates anti-inflammatory and anti-thrombogenic effects of pigment epithelium-derived factor in myeloma cells. Biochem Biophys Res Commun 443: 847-851, 2014.

28. Matsui T, Higashimoto Y, Nishino Y, Nakamura N, Fukami K and Yamagishi SI: RAGE-aptamer blocks the development and progression of experimental diabetic nephropathy. Diabetes 66: 1683-1695, 2017.

29. Nakamura N, Matsui T, Ishibashi Y, Sotokawauchi A, Fukami K, Higashimoto Y and Yamagishi SI: RAGE-aptamer attenuates the growth and liver metastasis of malignant melanoma in nude mice. Mol Med 23: 295-306, 2017.

30. Saika K and Sobue T: Epidemiology of breast cancer in Japan and the US. JMAJ 52: 39-44, 2009.

31. Akram M, Iqbal M, Daniyal M and Khan AU: Awareness and current knowledge of breast cancer. Biol Res 50: 33, 2017.
32. Peairs KS, Barone BB, Snyder CF, Yeh HC, Stein KB, Derr RL, Brancati FL and Wolff AC: Diabetes mellitus and breast cancer outcomes: A systematic review and meta-analysis. J Clin Oncol 29: 40-46, 2011.

33. Wang M, Yang Y and Liao Z: Diabetes and cancer: Epidemiological and biological links. World J Diabetes 11: 227-238, 2020.

34. Yamagishi S, Matsui T and Fukami K: Role of receptor for advanced glycation end products (RAGE) and its ligands in cancer risk. Rejuvenation Res 18: 48-56, 2015.

35. Matou-Nasri S, Sharaf H, Wang Q, Almobadel N, Rabhan Z, Al-Eidi H, Yahya WB, Trivilegio T, Ali R, Al-Shanti N and Ahmed N: Biological impact of advanced glycation endproducts on estrogen receptor-positive MCF-7 breast cancer cells. Biochim Biophys Acta Mol Basis Dis 1863: 2808-2820, 2017.

36. Lee KJ, Yoo JW, Kim YK, Choi JH, Ha TY and Gil M: Advanced glycation end products promote triple negative breast cancer cells via ERK and NF- $\kappa$ B pathway. Biochem Biophys Res Commun 495: 2195-2201, 2018

37. Walter KR, Ford ME, Gregoski MJ, Kramer RM, Knight KD, Spruill L, Nogueira LM, Krisanits BA, Phan V, La Rue AC, et al: Advanced glycation end products are elevated in estrogen receptor-positive breast cancer patients, alter response to therapy, and can be targeted by lifestyle intervention. Breast Cancer Res Treat 173: 559-571, 2019.

38. Omofuma OO, Turner DP, Peterson LL, Merchant AT, Zhang J and Steck SE: Dietary advanced glycation end-products (AGE) and risk of breast cancer in the prostate, lung, colorectal and ovarian cancer screening trial (PLCO). Cancer Prev Res (Phila) 13: 601-610, 2020.

39. Peterson LL, Park S, Park Y, Colditz GA, Anbardar N and Turner DP: Dietary advanced glycation end products and the risk of postmenopausal breast cancer in the national institutes of health-AARP diet and health study. Cancer 126: 2648-2657, 2020.

40. Hao L, Zhang C, Qiu Y, Wang L, Luo Y, Jin M, Zhang Y, Guo TB, Matsushima K and Zhang Y: Recombination of CXCR4, VEGF, and MMP-9 predicting lymph node metastasis in human breast cancer. Cancer Lett 253: 34-42, 2007.

41. Schneider BP and Sledge GW Jr: Drug insight: VEGF as a therapeutic target for breast cancer. Nat Clin Pract Oncol 4: 181-189, 2007.

42. Dofara SG, Chang SL and Diorio C: Gene polymorphisms and circulating levels of MMP-2 and MMP-9: A review of their role in breast cancer risk. Anticancer Res 40: 3619-3631, 2020.

43. Nakamura N, Matsui T, Nishino Y, Sotokawauchi A, Higashimoto Y and Yamagishi SI: Long-term local injection of RAGE-aptamer suppresses the growth of malignant melanoma in nude mice. J Oncol 2019: 7387601, 2019.

44. Yamagishi S, Abe R, Inagaki Y, Nakamura K, Sugawara H, Inokuma D, Nakamura H, Shimizu T, Takeuchi M, Yoshimura A, et al: Minodronate, a newly developed nitrogen-containing bisphosphonate, suppresses melanoma growth and improves survival in nude mice by blocking vascular endothelial growth factor signaling. Am J Pathol 165: 1865-1874, 2004.

45. Yamagishi S and Imaizumi T: Diabetic vascular complications: Pathophysiology, biochemical basis and potential therapeutic strategy. Curr Pharm Des 11: 2279-2299, 2005.

46. Gutsche K, Randi EB, Blank V, Fink D, Wenger RH, Leo C and Scholz CC: Intermittent hypoxia confers pro-metastatic gene expression selectively through NF- $\kappa \mathrm{B}$ in inflammatory breast cancer cells. Free Radic Biol Med 101: 129-142, 2016.

47. Lewis K, Kiepas A, Hudson J, Senecal J, Ha JR, Voorand E, Annis MG, Sabourin V, Ahn R, La Selva R, et al: p66ShcA functions as a contextual promoter of breast cancer metastasis. Breast Cancer Res 22: 7, 2020.

48. Jia L, Huang S, Yin X, Zan Y, Guo Y and Han L: Quercetin suppresses the mobility of breast cancer by suppressing glycolysis through Akt-mTOR pathway mediated autophagy induction. Life Sci 208: 123-130, 2018.

49. Yamagishi S, Inagaki Y, Nakamura K, Abe R, Shimizu T, Yoshimura A and Imaizumi T: Pigment epithelium-derived factor inhibits TNF-alpha-induced interleukin- 6 expression in endothelial cells by suppressing NADPH oxidase-mediated reactive oxygen species generation. J Mol Cell Cardiol 37: 497-506, 2004

50. Hou J, Ge C, Cui M, Liu T, Liu X, Tian H, Zhao F, Chen T, Cui Y, Yao M, et al: Pigment epithelium-derived factor promotes tumor metastasis through an interaction with laminin receptor in hepatocellular carcinomas. Cell Death Dis 8: e2969, 2017. 
51. Yamagishi S, Matsui $\mathrm{T}$ and Inoue $\mathrm{H}$ : Inhibition by advanced glycation end products (AGEs) of pigment epithelium-derived factor (PEDF) gene expression in microvascular endothelial cells. Drugs Exp Clin Res 31: 227-232, 2005.

52. Ide Y, Matsui T, Ishibashi Y, Takeuchi $M$ and Yamagishi S: Pigment epithelium-derived factor inhibits advanced glycation end product-elicited mesangial cell damage by blocking NF-kappaB activation. Microvasc Res 80: 227-232, 2010.
53. Ishibashi Y,Matsui T, Ohta K, Tanoue R, Takeuchi M, Asanuma K, Fukami K, Okuda S, Nakamura K and Yamagishi S: PEDF inhibits AGE-induced podocyte apoptosis via PPAR-gamma activation. Microvasc Res 85: 54-58, 2013. 